\title{
On the Necessity of the Development of Jingdezhen Film and Television Tourism from the Famous Japanese Tourist program "Impression of Tokyo"
}

\author{
Yu Wu and Danyu Wu
}

(School of Foreign Language, Jingdezhen Ceramic Institute, Jingdezhen, Jiangxi Province, 333403; School of Marxism, Jingdezhen Ceramic Institute, Jingdezhen, Jiangxi, 333403)

Keywords: Impression of Tokyo; travel; TV communication; Jingdezhen

\begin{abstract}
As one of the outstanding symbols of Chinese history and culture, Jingdezhen ceramic art has played an indispensable role in the dissemination of traditional culture since ancient times. With the rapid development of the times, more and more traditional culture is getting far away from people's daily life while being gradually ignored by the public, which is obviously unfavorable for carrying forward the spirit of China and inheriting culture. In this paper, the "Impression of Tokyo" program is taken as an example to analyze the reasons for the success of this program and limitations in the development process as a reference for TV communication of Jingdezhen ceramics.

It has been 10 years since the cultural and travel TV program "Impression of Tokyo" was first shown at Shanghai Life and Fashion TV channel in front of TV audiences in January 2005. In the past ten years, this program, which is mainly titled with the name Tokyo, has also introduced the features of many other places in Japan, including classic and magnificent holy land for travel, unexpected countryside scenery, beautiful and gorgeous theme shops and mouthwatering specialties, etc. While introducing the features of Japan, it also disseminates knowledge about the Japanese history and culture so that audiences can also learn new knowledge while enjoying the beauty. Thus, it is a cultural and travel program worth recommendation. In contract, China's traditional culture is also extensive and profound with a long history, such as the Jingdezhen ceramic culture with rich connotations [1]. Nowadays, with the burst of massive information, it is more necessary to widely spread these cultures, and as the most intuitive and influential means of media, TV communication will undoubtedly greatly influence the dissemination of Jingdezhen ceramic culture. Then, in order to learn what references we can draw from the success of the excellent TV program: "Impression of Tokyo" in spreading China's Jingdezhen ceramic culture, we should first accurately analyze factors contributing to the success of this program.
\end{abstract}

\section{Reflection on TV Communication of Jingdezhen Ceramic Culture in the Production of "Impression of Tokyo"}

\section{Programs in TV Communication Should Have Compact Structure and Clear Thoughts}

A popular TV program should first convey more contents to audiences within the limited time so as to make audiences have the feeling of dizzying. Then, they will focus on the program. "Impression of Tokyo" is very good in this regard. In a regular program, led by the host's explanation, audiences can shuttle between different scenes demonstrating the current themes, and audiences sitting in front of the TV can get immersive feelings in different scenes. In addition, compact structure will make the program itself rich and full in contents without procrastination, which is particularly important with the increasingly fierce competition between entertainment programs. With compact structure, "Impression of Tokyo" also brings a clear thought for audiences. For example, in a program introducing the famous tourist site in Japan - Kameoka, after the host explains the next destination with great anticipation, a complete route will be shown in the program accordingly so that audiences can more accurately remember them, and this also realizes the true significance of travel programs [2], i.e., to bring audiences effective and feasible information. Similarly, it is very necessary to have compact structure and clear thought in the TV communication of China's 
Jingdezhen ceramic culture. Traditional cultures will undoubtedly bring us the enjoyment of beauty, but their beauty need deep experience. If the TV program does not effectively and clearly disseminate the contents, it will make audiences have vague feelings when they do not understand the contents. The production of a TV program needs a lot of manpower and financial resources, but if half effect is achieved with doubled efforts, it is not worth the candle.

\section{Programs in TV Communication Should in Various Production Forms with Appropriate Length}

For "Impression of Tokyo", the time limit of every program is about half an hour and different forms are used in this process to show the theme. It is indeed not long for an entertainment program to last for 30 minutes, but it is a difficult problem for the crew as how to introduce more contents within such short time and attract more audiences. However, in "Impression of Tokyo", through the conversion of many scenarios, interviews with local residents, tourists and manufacturers, the crew introduce audiences with detailed findings at the localities, thus enriching the program's contents and also making the thirty minutes transient. Then, audiences long for more. In fact, in the production of each program, the crew also has to cut many screens due to the limited time, but this strict selection makes the program contents become more excellent, thus "Impression of Tokyo" can still survive ten years later with the fierce competition with similar programs. We often have this feeling that the food and the destinations in TV programs are more attractive than in our actual travel. The host's attractive explanation is undoubtedly one of the main reasons, and another reason is that we often feel one aspect of things, but these things are demonstrated in TV programs objectively. Similarly, we should also notice this in the TV communication of Jingdezhen ceramic culture. It is necessary to enrich the program forms in order to guarantee the fun so that audiences will not have visual fatigue, then the communication effect and culture tastes can be enhanced.

Programs in TV Communication Should Pass Cultural Connotations with Profound Meaning

With more and more TV programs demonstrated in the majority of audiences, there are more and more ways for people to relax and fore entertainment. However, on the TV screens, the majority of TV programs are entertainment programs such as interviews with stars, reality shows and singing contests, etc. and there are only few high-quality cultural programs such as "Impression of Tokyo". Nowadays, with the improved quality of people and gradually improved cultural level, to add more intensive and profound programs on history and culture in the wide range of entertainment programs represents the strong desire of the broad masses of TV audiences. In "Impression of Tokyo", when the crews get to every pleasant holy land full of local conditions and customs, they will interpret the local historical and cultural knowledge and memorable symbols to meticulously convey culture to audiences. On the other hand, people from all walks of life related to the theme of the program will be interviewed. For example, in one program, the crew visited a local vegetarian supermarket to introduce distinctive local fresh fruits and vegetables and shoot the scene that everyone was enthusiastically purchasing goods. Such enthusiasm reflected the vegetarian supermarket's professional and attentive services. The detailed production information is labeled on every commodity, even including the name of the individual manufacturers. Thus, the commodities can be traced and buyers will feel more assured in purchasing. From this program, audiences cannot only learn relevant cultural knowledge, but also get to know and use the industrial features in different countries and regions. If the grade and security standards of commercial food in China can also be traced, this will undoubtedly make beneficial contributions to guaranteeing the security of food. From "Impression of Tokyo", we can think about cultural issues and associate them with our own lives, which is an unexpected result this program brings to us as well as the extension of this program's connotation. Therefore, to achieve TV communication of Jingdezhen ceramic culture effectively and pass contents of TV programs to audiences is not only an indirect way to protect traditional culture and an important means to enrich audiences' entertainment life, but also a way that allows audiences to think about life in detail.

Such a good cultural and travel program deserves to be more widely respected and disseminated and should be emulated and studied, especially for those traditional cultures that in urgent need to 
be promoted in the right way. The ancient saying "Good wine needs no bush" now seems to be not applicable to traditional culture, especially the culture with a small group of audiences like the ceramic art. They are excellent results accumulated in the five thousand years of China's ancient civilization, but are being gradually forgotten with the rapid development of the times. The neglect of the ceramic culture is one of the reasons causing the loss of intangible cultural heritage [3], which will also bleak the great glory of our traditional culture. Jingdezhen ceramic culture needs to be widely disseminated, and it is not the responsibility for just one generation to inherit and carry forward Jingdezhen ceramic culture, but it needs the efforts of our generation. To this end, the limitations in the development process of "Impression of Tokyo" should also be considered so as to play a warning role in the wide communication of Jingdezhen ceramic culture.

\section{Limitations of "Impression of Tokyo" in TV Communication}

\section{Limited Scope of Audiences}

There is no doubt that an effective platform is needed to publicize and broadcast a good program. "A Bite of China" could have extensive influence in the beginning when it was broadcasted, which is inseparable from the communication platform of CCTV. Although the program "Impression of Tokyo" appropriately combines entertainment and culture, it is only broadcasted on a local TV station, thus limiting the communication effect to some extent. Jingdezhen ceramic culture is a traditional Chinese culture. Therefore, in order to achieve effective TV communication, while focusing on entertainment, we should also pay attention to the effectiveness of the communication platform. Only when the influence of communication is expanded, more audiences can get to know the porcelain capital and the charm of Jingdezhen ceramic culture.

\section{Slightly Inadequate Publicity Efforts}

How to make audiences have a relatively profound understanding of the program before TV communication is also a very important aspect. Nowadays, several months before the broadcasting of many entertainment programs, promos, advertising, celebrities' news and other forms of publicity campaign are used for promotion, which also well promote the programs. However, for relatively conservative programs about traditional culture, how to increase publicity efforts and innovate the publicity forms is also a problem worth deep reflection of TV program workers. For cultural programs, the publicity should be appropriate and flexible without blindly pursuing the publicity effort or ignoring the importance of publicity. It will be a good choice to effectively combine the network platform and use advertising inter-cuts before videos are broadcasted on video sites so as to publicize programs.

\section{Analysis on the Necessity of TV Communication in Jingdezhen Ceramic Culture}

The rapid development of economy has also accelerated everyone's pace of life, but we need to timely stop to feel the abundance and happiness brought by the beauty of nature, which is probably the initial intention that "Impression of Tokyo" will pass to every audience. At the same time, we should also apply what we have learned into practice by applying the successful elements of "Impression of Tokyo" in TV communication of Jingdezhen ceramic culture, which is not only to inherit and carry forward China's ceramic culture, but can also set a positive example for TV communication of traditional Chinese culture. Besides, it is a meaningful responsible for the TV and media industry nowadays when it is urgent to protect traditional culture.

\section{Acknowledgement}

The research of this paper is funded by "Reflections on TV Communication of Jingdezhen Ceramic Culture-An Analysis from the Perspective of the Creation of 'Impression of Tokyo"'(Subject of Jingdezhen science and technology bureau, Number 753007-002 ). 


\section{References}

[1] WU Xiumei, Cultural Path of Ceramic Inheritance [J]. Journal of Nanjing Arts University, 2012 (6): $138-140$

[2] LIANG Jinghe. Fragmentary Recollections of Impression of Tokyo [J]. Journal of Capital Normal University, 2004 (z2): 182-194

[3]DENG Yajuan, TIAN Hongxi. A Study on the Inheritance of Jingdezhen Ceramic Intangible Cultural Heritage from the Perspective of Cultural Communication - A Case Study of Jingdezhen Traditional Handicrafts [J]. Artistic Life - Theory of Literature and Art, 2014 (9): 17-19 